\title{
POLÍTICAS PÚBLICAS NO BRASIL: revisão sistemática da literatura
}

PUBLIC POLICIES IN BRAZIL: systematic literature review

POLIITICAS PÚBLICAS EN BRASIL: revisión sistemática de la literatura

\section{Airton Cardoso Cançado}

Doutorado em Administração pela Universidade Federal de Lavras (UFLA). Professor Adjunto da Universidade Federal do Tocantins (UFT). airtoncardoso@yahoo.com.br.

0000-0003-4698-1804

\section{Fabiane Santos Barros}

Mestrado profissional em andamento em Gestão de Políticas Públicas na Universidade Federal do Tocantins (UFT). fabianesantosbarros@gmail.com.

0000-0001-9496-8132

\section{Fernando Santos Barros}

Mestrado em Profissional em administração Pública PROFIAP na Universidade Federal do Tocantins (UFT). contnando@mail.uft.edu.br.

\section{0-0003-4051-6573}

Correspondência: Universidade Federal do Tocantins, Programa de Pós-Graduação em Desenvolvimento Regional. Av NS 15 ALC NO 14, Bloco 3, sala 33, Campus Universitário. 77001090 - Palmas, TO - Brasil

Recebido em: 12.10.2020.

Aceito em: 20.11.2020.

Publicado em: 01.01.2021.

\begin{abstract}
RESUMO:
Este estudo teve como objetivo analisar a evolução das políticas públicas no Brasil no período de 2010 a 2019, sob a ótica do seu desenvolvimento, o envolvimento dos atores e movimentos sociais e o desenvolvimento das fases do ciclo de políticas públicas. Foram identificados trinta estudos relevantes e em conformidade com a problemática abordada. A análise possibilitou a divisão dos artigos em eixos temáticos, a fim de uma melhor exposição dos resultados e discussão, sendo eles: contexto das políticas públicas no Brasil, atores e movimentos sociais e ciclo de políticas públicas. Pode-se considerar recente a análise de políticas públicas no Brasil, porém com grandes avanços que sobrevieram a partir da Constituição Federal.
\end{abstract}

PALAVRAS-CHAVES: Gestão Pública. Políticas Públicas. Ciclo de Políticas Públicas.

\section{Introdução}

Com a expansão da democracia, o Estado teve como função o bem-estar da sociedade, para promover isso, ele utiliza as políticas públicas. Compreender o sentido do termo políticas públicas é o primeiro passo para entender a importância desse instrumento para a sociedade. Existem várias definições para esse termo, porém uma ideia central entre elas é que o agente mais importante do processo de produção de políticas públicas é o governo, para Smith e Larimer (2009), as políticas públicas envolvem o processo de fazer escolhas e o que as torna públicas, é que essas escolhas se baseiam nos poderes coercitivos do Estado.

Para esta pesquisa, foi utilizado o conceito de políticas públicas descrito por Secchi, Coelho e Pires (2019), que se constitui em uma orientação para resolver um problema entendido como coletivamente público, possui dois elementos fundamentais, a intencionalidade pública e resposta a um problema público, este é considerado como a diferença do estado atual e do que pode ser feito para chegar a uma situação ideal, para ele ser público é necessário ter implicações para uma quantidade ou qualidade de pessoas (SECCHI; COELHO; PIRES, 2019). 
As políticas públicas se materializam por meio de programas, diretrizes, projetos, decretos, entre outros, buscando atender as demandas em comum da sociedade, de forma "pública" para garantir o acesso amplo.

Fundamentado na importância das políticas públicas para o desenvolvimento do estado e do bem-estar da sociedade, este estudo objetiva analisar a evolução das políticas públicas no Brasil no período de 2010 a 2019, sob a ótica do seu desenvolvimento, o envolvimento dos atores e movimentos sociais e o desenvolvimento das fases do ciclo de políticas públicas.

O artigo segue estruturado em quatro seções: após esta introdução, a segunda seção trata dos aspectos metodológicos; a terceira apresenta os eixos temáticos, a partir da análise qualitativa dos artigos, por fim, a quarta, apresenta uma síntese dos principais achados do estudo nas considerações finais.

\section{Aspectos metodológicos}

Para viabilizar o desenvolvimento deste estudo, optou-se por uma revisão sistemática de natureza qualitativa. A revisão sistemática é um delineamento de evidências provenientes de estudos primários para responder uma questão específica de pesquisa, para isso utiliza-se um processo de revisão de literatura abrangente, imparcial e reprodutível, que localiza, avalia e sintetiza estudos anteriores (BORK, 2005; BRASIL, 2012).

Esse tipo de pesquisa é uma maneira de agrupar conhecimento sobre um determinado assunto, facilitando o trabalho dos pesquisadores. Requer um extenso esforço de classificação e encontro de trabalhos que sejam relevantes (KITCHENHAM; CHARTERS, 2007).

De acordo com Galvão e Pereira (2014), para a elaboração de uma revisão sistemática é necessário realizar as seguintes etapas: elaboração da pergunta de pesquisa/objetivo, busca na literatura, seleção dos artigos, extração dos dados, avaliação da qualidade metodológica; síntese dos dados ou metanálise, avaliação da qualidade das evidências e redação e publicação dos resultados.

$\mathrm{Na}$ primeira etapa definiu-se a questão norteadora, sendo: Como se deu o desenvolvimento das políticas públicas no Brasil nos últimos 10 anos? Na segunda etapa foi realizada à busca na literatura, utilizando o banco de dados Scientific Electronic Library Online (SCIELO) e SCOPUS (base de dados bibliográficos) no portal de periódicos da Coordenação de Aperfeiçoamento de Pessoal de Nível Superior (CAPES) entre os anos de 2010 e 2019, a busca foi realizada em abril de 2020. 
$\mathrm{Na}$ terceira etapa os artigos foram selecionados a partir do descritor "Políticas Públicas" por meio da técnica de pesquisa bibliométrica nas bases escolhidas, caracterizado pela escolha intencional, que estivessem disponíveis, se encaixassem no objetivo da pesquisa e a revista tivesse qualis igual ou superior a B1 de acordo com avaliação do quadriênio 2013-2016 disponível na plataforma Sucupira da CAPES (CAPES, 2020). Na figura 1, foi ilustrada a seleção dos artigos.

Figura 1 - Artigos selecionados nas bases de dados SCIELO e SCOPUS entre os anos 2010 a 2019:
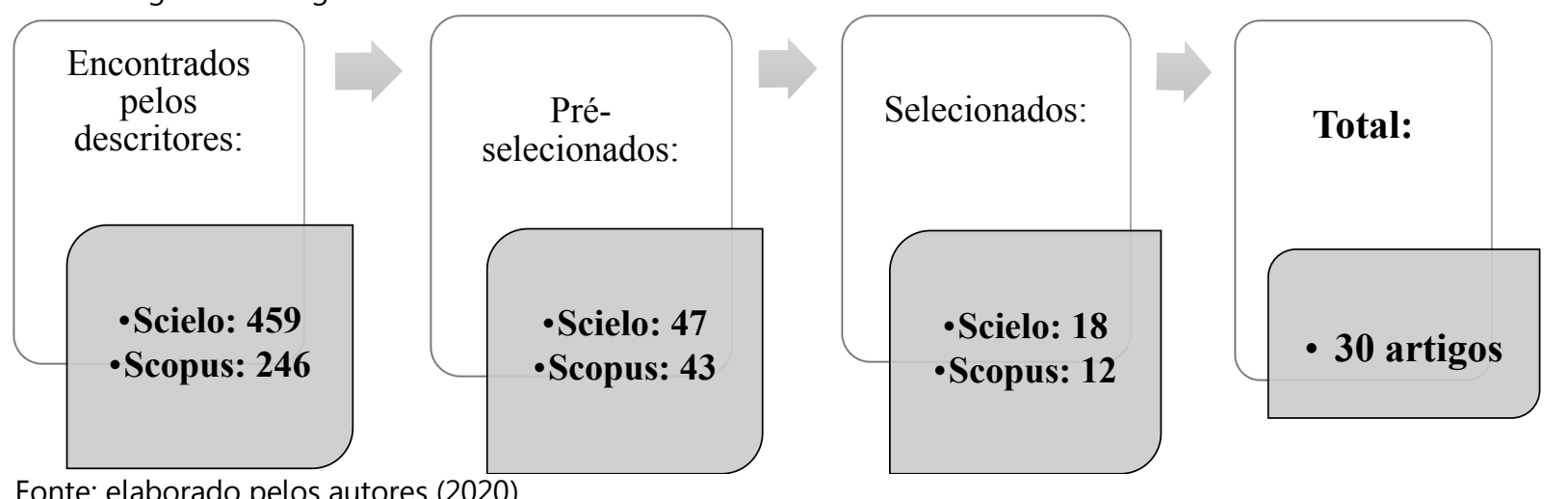

Na próxima seção serão abordados os resultados e a discussão obtidos após seguir a metodologia proposta.

\section{Resultados e Discussão}

Conforme o objetivo proposto e a metodologia de pesquisa utilizada, foram identificados trinta estudos relevantes e em conformidade com a problemática abordada. Com o intuito de auxiliar na visualização dos principais resultados dos artigos selecionados foram catalogadas no Quadro 1 as seguintes informações: base de dados, ano de publicação, título e metodologia.

\begin{tabular}{|c|c|c|c|}
\hline $\begin{array}{l}\text { BASE DE } \\
\text { DADOS }\end{array}$ & AUTORES/ ANO & & TÍTULO \\
\hline \multirow{4}{*}{ SCIELO } & $\begin{array}{l}\text { Oliveira; Passador } \\
\text { (2019) }\end{array}$ & 1 & $\begin{array}{l}\text { Ensaio teórico sobre as avaliações de políticas } \\
\text { públicas }\end{array}$ \\
\hline & $\begin{array}{l}\text { Almeida; Gomes } \\
\qquad(2018)\end{array}$ & 2 & $\begin{array}{l}\text { Processo das políticas públicas: revisão de literatura, } \\
\text { reflexões teóricas e apontamentos para futuras } \\
\text { pesquisas }\end{array}$ \\
\hline & $\begin{array}{l}\text { Valle } \\
(2018)\end{array}$ & 3 & $\begin{array}{c}\text { Planejamento orçamentário e políticas públicas: } \\
\text { explorando uma alternativa de reconciliação pela } \\
\text { indução }\end{array}$ \\
\hline & Petinelli (2017) & 4 & $\begin{array}{l}\text { A quem servem as conferências de políticas públicas? } \\
\text { Desenho institucional e atores beneficiados }\end{array}$ \\
\hline
\end{tabular}




\begin{tabular}{|c|c|c|c|}
\hline & $\begin{array}{l}\text { Santos; Ribeiro; } \\
\text { Ribeiro; Pinto } \\
\text { (2017) }\end{array}$ & 5 & $\begin{array}{c}\text { Administração política e políticas públicas: em busca } \\
\text { de uma nova abordagem teórico-metodológica para } \\
\text { a (re)interpretação das relações sociais de produção, } \\
\text { circulação e distribuição }\end{array}$ \\
\hline & $\begin{array}{l}\text { Batista; Domingos } \\
\text { (2017) }\end{array}$ & 6 & $\begin{array}{c}\text { Mais que boas intenções: técnicas quantitativas e } \\
\text { qualitativas na avaliação de impacto de políticas } \\
\text { públicas }\end{array}$ \\
\hline & $\begin{array}{l}\text { Chaebo; Medeiros } \\
\text { (2017) }\end{array}$ & 7 & $\begin{array}{c}\text { Reflexões conceituais em coprodução de políticas } \\
\text { públicas e apontamentos para uma agenda de } \\
\text { pesquisa }\end{array}$ \\
\hline & $\begin{array}{l}\text { Pogrebinschi; } \\
\text { Ventura } \\
\text { (2017) }\end{array}$ & 8 & $\begin{array}{c}\text { Mais Participação, Maior Responsividade? As } \\
\text { Conferências Nacionais de Políticas Públicas e a } \\
\text { Qualidade da Democracia no Brasil }\end{array}$ \\
\hline & $\begin{array}{l}\text { Miranda; Mendes; } \\
\text { Silva } \\
\text { (2016) }\end{array}$ & 9 & $\begin{array}{l}\text { Desafios das políticas públicas no cenário de } \\
\text { transição demográfica e mudanças sociais no Brasil }\end{array}$ \\
\hline & $\begin{array}{l}\text { Couto; Lima } \\
\text { (2016) }\end{array}$ & 10 & $\begin{array}{l}\text { Continuidade de Políticas Públicas: A } \\
\text { Constitucionalização Importa? }\end{array}$ \\
\hline & $\begin{array}{l}\text { Macedo; Alcântara; } \\
\text { Andrade; Ferreira } \\
\text { (2016) }\end{array}$ & 11 & $\begin{array}{c}\text { O papel dos atores na formulação e implementação } \\
\text { de políticas públicas: dinâmicas, conflitos e interesses } \\
\text { no Programa Mais Médicos }\end{array}$ \\
\hline & $\begin{array}{l}\text { Bichir } \\
(2015)\end{array}$ & 12 & Olhares cruzados nas análises de políticas públicas \\
\hline & $\begin{array}{l}\text { Freitas } \\
(2015)\end{array}$ & 13 & $\begin{array}{l}\text { Políticas públicas, descentralização e participação } \\
\text { popular }\end{array}$ \\
\hline & $\begin{array}{l}\text { Fonseca } \\
(2013)\end{array}$ & 14 & Dimensões críticas das políticas públicas \\
\hline & $\begin{array}{l}\text { Maciel } \\
(2013)\end{array}$ & 15 & $\begin{array}{l}\text { Finanças públicas no Brasil: uma abordagem } \\
\text { orientada para políticas públicas }\end{array}$ \\
\hline & $\begin{array}{l}\text { Silva } \\
(2012)\end{array}$ & 16 & Políticas públicas e administração democrática \\
\hline & $\begin{array}{l}\text { Ollaik; Medeiros } \\
\qquad(2011)\end{array}$ & 17 & $\begin{array}{l}\text { Instrumentos governamentais: reflexões para uma } \\
\text { agenda de pesquisas sobre implementação de } \\
\text { políticas públicas no Brasil }\end{array}$ \\
\hline & $\begin{array}{l}\text { Nascimento } \\
\quad(2010)\end{array}$ & 18 & $\begin{array}{l}\text { Reflexões sobre a intersetorialidade entre as políticas } \\
\text { públicas }\end{array}$ \\
\hline & $\begin{array}{l}\text { Souza } \\
(2019)\end{array}$ & 19 & $\begin{array}{l}\text { Coordenação, uniformidade e autonomia na } \\
\text { formulação e implementação de políticas públicas: a } \\
\text { experiência federal no Brasil e no exterior }\end{array}$ \\
\hline & $\begin{array}{l}\text { Dowbor; Carlos; } \\
\text { Albuquerque } \\
\text { (2018) }\end{array}$ & 20 & $\begin{array}{l}\text { As origens movimentistas de políticas públicas: } \\
\text { proposta analítica aplicada às áreas de criança e } \\
\text { adolescente, direitos humanos e saúde }\end{array}$ \\
\hline SCOPUS & $\begin{array}{l}\text { Abers; Silva; } \\
\text { Tatagiba (2018) }\end{array}$ & 21 & $\begin{array}{l}\text { Movimentos sociais e políticas públicas: repensando } \\
\text { atores e oportunidades políticas. }\end{array}$ \\
\hline & $\begin{array}{l}\text { Farah } \\
(2016)\end{array}$ & 22 & $\begin{array}{c}\text { Análise de políticas públicas no Brasil: de uma prática } \\
\text { não nomeada à institucionalização do "campo de } \\
\text { públicas" }\end{array}$ \\
\hline & $\begin{array}{l}\text { Crumpton; } \\
\text { Medeiros; Ferreira; } \\
\text { Sousa; Najberg } \\
(2016)\end{array}$ & 23 & $\begin{array}{l}\text { Avaliação de políticas públicas no Brasil e nos Estados } \\
\text { Unidos: análise da pesquisa nos últimos } 10 \text { anos }\end{array}$ \\
\hline
\end{tabular}




\begin{tabular}{|c|c|c|}
\hline $\begin{array}{l}\text { Lotta; Favareto } \\
\qquad(2016)\end{array}$ & 24 & $\begin{array}{l}\text { Desafios da integração nos novos arranjos } \\
\text { institucionais de políticas públicas no Brasil }\end{array}$ \\
\hline $\begin{array}{l}\text { Petinelli } \\
\text { (2015) }\end{array}$ & 25 & $\begin{array}{c}\text { Aferindo a capacidade de influência das conferências } \\
\text { de políticas públicas sobre os programas das } \\
\text { respectivas políticas setoriais. }\end{array}$ \\
\hline $\begin{array}{l}\text { Lima; D'Ascenzi } \\
\qquad(2013)\end{array}$ & 26 & $\begin{array}{l}\text { Implementação de políticas públicas: perspectivas } \\
\text { analíticas }\end{array}$ \\
\hline $\begin{array}{l}\text { Fragelli; Shimizu } \\
\text { (2013) }\end{array}$ & 27 & $\begin{array}{c}\text { Prospecções para desenvolvimento de políticas } \\
\text { públicas de formação de profissionais de saúde a } \\
\text { partir da análise do cenário brasileiro de } \\
\text { competências. }\end{array}$ \\
\hline $\begin{array}{l}\text { Barata } \\
(2013)\end{array}$ & 28 & Epidemiologia e políticas públicas \\
\hline $\begin{array}{l}\text { Ramos; Schabbach } \\
\text { (2012) }\end{array}$ & 29 & $\begin{array}{l}\text { O estado da arte da avaliação de políticas públicas: } \\
\text { conceituação e exemplos de avaliação no Brasil. }\end{array}$ \\
\hline $\begin{array}{l}\text { Vaz } \\
(2011)\end{array}$ & 30 & $\begin{array}{l}\text { Participação política, efeitos e resultados em políticas } \\
\text { públicas: notas crítico-analíticas }\end{array}$ \\
\hline
\end{tabular}

Fonte: elaborado pelos autores (2020).

Entre os artigos selecionados, notou-se que esses fazem parte de quinze revistas científicas de alto impacto, com o maior quantitativo em duas revistas de Qualis Capes A2 (Avaliação 2013-2016): Caderno da Escola Brasileira de Administração Pública e de Empresas da Fundação Getúlio Vargas (Cadernos EBAPE.BR) e Revista de Administração Pública (RAP).

Quadro 2 - Qualis CAPES das revistas que os artigos selecionados foram publicados:

\begin{tabular}{|c|c|c|}
\hline QUALIS & Revistas & Quantidade \\
\hline A2 & Cadernos EBAPE.BR & 6 \\
\hline A2 & Revista de Administração Pública & 5 \\
\hline B1 & Opinião Publica & 3 \\
\hline B1 & Lua Nova & 2 \\
\hline B1 & Revista Brasileira de Ciências Sociais & 2 \\
\hline B1 & Revista de Sociologia e Política & 2 \\
\hline A2 & Dados & 2 \\
\hline B1 & Interface (Botucatu) & 1 \\
\hline B1 & Physis: Revista de Saúde Coletiva & 1 \\
\hline B1 & Revista Brasileira de Epidemiologia & 1 \\
\hline B1 & Sequência (Florianópolis) & 1 \\
\hline B1 & Serviço Social \& Sociedade & 1 \\
\hline A2 & Caderno Saúde Pública & 1 \\
\hline A2 & Revista Katálysis & 1 \\
\hline A1 & Revista de Investigações Constitucionais & 1 \\
\hline
\end{tabular}

Fonte: Adaptado do site plataforma sucupira (Qualis periódicos) (2020). 
A análise possibilitou a divisão dos artigos em eixos temáticos, a fim de uma melhor exposição dos resultados e discussão, sendo eles: contexto das políticas públicas no Brasil (10), atores e movimentos sociais (9) e ciclo de políticas públicas (11). Estes foram identificadas após análise descritiva e qualitativa da amostra bibliográfica.

Quadro 3 - Classificação dos artigos selecionados:

\begin{tabular}{|c|c|}
\hline Eixos temáticos & Artigos \\
\hline Contexto das políticas públicas no Brasil & $2,3,5,9,14,15,16,18,22,24$ \\
\hline Atores e movimentos sociais & $4,8,11,13,20,21,25,27,30$ \\
\hline Ciclo de Políticas Públicas & $1,6,7,10,12,17,19,23,26,28,29$ \\
\hline
\end{tabular}

Fonte: elaborado pelos autores (2020).

Os resultados e discussão seguem divididos em subtítulos a partir dos eixos temáticos elencados no quadro 3.

Contexto das políticas públicas no Brasil

Nesse eixo, buscou-se entender o que compõe o contexto das políticas públicas no território brasileiro, para isso, foram analisados dez artigos.

A análise de políticas ocorre no Brasil a partir dos anos 1930. (FARAH, 2016). A maior produção cientifica vêm do exterior, o que implica a ausência de particularidades da realidade brasileira como a tendência de se analisar as políticas públicas nacionais na ótica de outras realidades incapazes de se adaptar a instituições, atores, cultura política, entre outros fatores que são típicos no Brasil, o que acaba negligenciando algumas questões (FONSECA, 2013).

Outro aspecto que merece destaque é em relação a transição demográfica que a população brasileira está passando, com a inversão da pirâmide de faixa etária, por meio da redução das taxas de fecundidade, natalidade, mortalidade infantil e o aumento da esperança de vida ao nascer, consequentemente trouxe mudanças e desigualdades sociais de forma mais acentuada (MIRANDA; MENDES; SILVA, 2017).

Essas mudanças requerem políticas adequadas para que a demografia possa contribuir com o desenvolvimento econômico e social, do bem-estar da sociedade e do cuidado com o meio ambiente. Seria fundamental a implementação de políticas públicas que respondessem às necessidades geradas pelas rápidas transformações demográficas, como as políticas de saúde para uma boa qualidade de vida e envelhecimento saudável e a redução das iniquidades (MIRANDA; MENDES; SILVA, 2017). 
Um comparativo internacional observou que o Brasil gasta excessivamente recursos com previdência1, mesmo que a demografia brasileira ainda seja jovem. Essa tendência deverá se deteriorar no médio prazo, o que exigirá reformas nas regras de aposentadoria que convirjam para o padrão internacional. Em relação à Saúde, ao Trabalho e à Defesa, foi verificado que o montante de recursos alocados para esses setores segue próximo da média internacional (MACIEL, 2013).

Já a Educação foi o setor em que se observou a menor alocação de recursos do Brasil em relação aos demais países, o que é agravado quando se leva em consideração o perfil demográfico brasileiro. Dado o tamanho da carga tributária brasileira, verificase que há um amplo espaço para melhora da qualidade do gasto em todas as áreas do setor público (MACIEL, 2013).

Frente a isso, Lotta e Favareto (2016) destacam que nos últimos anos o governo federal brasileiro tem experimentado uma variedade de arranjos institucionais com o objetivo de produzir políticas públicas efetivas em um contexto nacional, onde é possível observar a presença de três componentes de destaque, a articulação de temáticas intersetoriais, a construção de modelos de gestão de políticas com coordenação entre os entes federativos e sociedade civil e a busca de enraizamento nos contextos locais de implementação das políticas.

A intersetorialidade das políticas públicas passou a ser uma dimensão valorizada à medida que não se observava a eficiência, a efetividade e a eficácia esperadas na implementação das políticas setoriais, primordialmente no que se refere ao atendimento das demandas da população e aos recursos disponibilizados para a execução das mesmas. Trazendo a articulação de saberes técnicos, já que os especialistas em determinada área passaram a integrar agendas coletivas e compartilhar objetivos comuns (NASCIMENTO, 2010).

Um grande empecilho para a execução das políticas públicas no Brasil é a dissociação entre planejamento orçamentário e as políticas públicas, a qual pode ser observada em diversas notícias originárias de autoridades executivas e de agentes do

\footnotetext{
${ }^{1}$ A reforma da previdência surgiu com da necessidade de fomentar a produtividade para diminuir ou viabilizar os custos relativos ao financiamento previdenciário para as gerações futuras. No Brasil, a necessidade da reforma decorre não apenas da necessidade da correção de distorções como também da necessidade de garantir a sustentabilidade fiscal a médio e longo prazo em um contexto de rápido e intenso envelhecimento populacional. Nesse sentido, observa-se que o país já enfrenta níveis de despesa elevados e com uma trajetória crescente e insustentável, bem como em patamar muito acima do que seria esperado em razão de sua estrutura demográfica atual, ou seja, mesmo não possuindo parcela tão elevada de idosos em sua população. Esses fatores pressionam a carga tributária nacional e diminuem o espaço para outros setores na composição do gasto público (COSTANZI et al., 2018).
} 
controle em relação a descontinuidades em ações públicas, frequentemente ocasionada pelas dificuldades de ordem orçamentária ausência ou insuficiência de previsão de recursos específicos, frustração ou desvios na execução desse mesmo orçamento quando existente a provisão (VALLE, 2018).

A administração pública é essencial em todas as etapas das políticas públicas para que as escolhas públicas se revelem eficientes e sejam aptas a alcançar os resultados pretendidos, não apenas pela administração, mas por toda a sociedade, é indispensável que a alocação de vontades se dê mediante a participação de seus legítimos interessados, principalmente no que toca à discussão e à definição das finalidades que cada política se dispõe a atender (SILVA, 2012).

Os vários modos de administrar as organizações sociais integram, obrigatoriamente as dimensões políticas e também acolhem as dimensões tecnológicos, como reflexo, pois, das possibilidades de materializar determinado projeto de uma sociedade (SANTOS et al., 2017). Para isso, a análise da capacidade de influência dos atores em função tanto dos recursos possuídos como das relações estabelecidas deve fazer parte da composição da agenda de pesquisa (ALMEIDA; GOMES, 2018).

As mudanças no cenário brasileiro destacadas por esses autores, demostram a importância da formulação, implementação e avaliação de políticas públicas, este processo demanda a participação e formação de atores e movimentos sociais os quais serão destacados no próximo eixo.

\section{Atores e movimentos sociais}

Neste eixo foram trabalhados nove artigos que abordaram a origem dos movimentos sociais, a participação em conferências de políticas públicas, como os atores colaboram com a formulação das políticas públicas.

Para Dowbor, Carlos e Albuquerque (2018), os movimentos sociais tiverem origem a partir de três termos: inovação social, alternativa e instrumento. A inovação social diz respeito aos projetos-piloto que buscam resolver problemas sociais para os quais não existem ainda respostas estruturadas em serviços públicos ou aos qual o poder público nunca dedicou atenção, para que isso ocorra é necessário que essas inovações operem como alternativas, para isso ela precisa abranger a viabilidade técnica, a congruência com os valores dos membros da comunidade de especialistas na área e com os limites orçamentários, além da aceitabilidade do público e receptividade dos políticos. Em competição com alternativas, a proposta do movimento poderá ou não ser adotada pelos governantes e gestores públicos como um instrumento de política pública. 
Os movimentos sociais, como expedientes da ação política, se constituíram, a partir da Constituição Federal de 1988, nos dois principais eixos orientadores de organização das políticas públicas. Com essa evolução o essencial ganhou forma e a valorização da democracia do poder local se fortaleceu (FREITAS, 2015).

A participação social e deliberativa já faz parte da democracia brasileira. As conferências de políticas públicas fazem parte desses espaços institucionais para debater e decidir diretrizes e prioridades de determinada política.

Essas conferências foram convocadas pelo Poder Executivo, frequentemente em parceria com a sociedade civil, possibilitando que ambos os lados juntos discutam e construam diretrizes, isto é, recomendações de políticas a serem possivelmente adotadas pelo governo em determinadas áreas. Estas são organizadas em torno de temas ou áreas de políticas e seguem um processo escalonado que tem início nos municípios, seguem para os estados federados por meio da eleição de delegados e da aprovação de diretrizes e, em seguida, é concluído com uma etapa nacional (POGREBINSCHI; VENTURA, 2017).

As conferências de políticas públicas têm servido enquanto espaços de inclusão de novas vozes no processo de discussão de políticas. Delas tem resultado um conjunto de propostas para as instituições competentes, que expressam, em menor ou maior medida, as demandas e os interesses das categorias nelas presentes. A capacidade de influência de cada setor é constrangida, porém, pelo desenho institucional do encontro, o qual pode tanto favorecer como limitar a participação e as oportunidades de decisão dos atores societais ao longo do processo (PETINELLI, 2017).

Enquanto espaços potencialmente plurais e democráticos, as conferências podem gerar resultados, muitas vezes, pouco representativos dessa diversidade, em decorrência da dinâmica representativa e deliberativa que estabelecem. Em contextos políticos menos permeáveis à participação, a relação entre desenho institucional e capacidade de influência dos atores torna-se ainda mais relevante, dados os potenciais ganhos inclusivos da implementação de arranjos participativos no bojo do processo de políticas públicas (PETINELLI, 2017).

Pogrebinschi e Ventura (2017) demonstraram como inovações democráticas, por meio da participação de cidadãos e de atores da sociedade civil, podem tornar as instituições representativas mais responsivas e, assim, ampliar a qualidade das democracias contemporâneas. Para tanto, formulou-se um modelo de análise do conceito de responsividade a partir de três níveis: impacto nas políticas públicas, congruência temática e igualdade e multidimensionalidade da representação.

No âmbito nacional, a ampliação da participação social e da influência dos atores societais nas decisões dos atores políticos pode ser atribuída, dentre outros motivos, à 
realização de conferências em um amplo e variado conjunto de políticas setoriais. Dos debates entre atores estatais e não estatais nessas arenas participativas, milhares de recomendações têm sido produzidas e encaminhadas para as instituições políticas competentes para ser incorporadas às respectivas políticas públicas (PETINELLI, 2015).

Para Freitas (2015), as normas de participação popular devem ser formuladas a partir de um amplo e democrático debate, porque deverá partir também da própria população organizada, a definição de agendas e espaços associativos autônomos como conselhos consultivos, consultas populares, fóruns, assembleias, conferências, congressos, articulados organicamente aos movimentos classistas. Deve-se entender a participação como um processo continuado com vistas à democratização dos negócios do governo e da administração pública.

As oportunidades e os constrangimentos confrontados pelos movimentos sociais na atuação nas políticas públicas passam a se enquadrar como produtos de agenciamentos simultâneos e recíprocos de diversos atores, redes e instituições, incluindo os próprios movimentos (ABERS; SILVA; TATAGIBA, 2018).

Quanto aos profissionais Macedo et al., (2016), Fragelli e Shimizu (2013) tratam da formação dos profissionais da saúde em detrimento das políticas públicas, considerando a necessidade de profissionais preparados para lidar com as novas demandas do setor. No caminho para a democratização do país, as políticas públicas possuem papel fundamental e precisam ser analisadas como campo multidisciplinar e ainda aberto a várias contribuições, olhares e perspectivas. Acredita-se que a contribuição principal foi caminhar na direção da constatação de que as políticas públicas se constituem de redes de interesses, conflitos, relações de poder, ideologias, disputa por recursos e legitimidade.

Segundo Vaz (2011), em cidades com maior propensão participativa, tende-se a encontrar, também, melhores resultados nos moldes considerados. Especialmente na área gerencial, esse fator é importante, já que este campo prediz a capacidade do governo local de elaborar, implementar, gerir, administrar, monitorar e avaliar políticas e resultados no seu território, contribuindo, principalmente, para a responsabilidade fiscal quanto aos gastos públicos e quanto à efetiva melhoria da "qualidade de vida" dos cidadãos.

O propósito desse eixo foi demonstrar que as políticas públicas podem ter origem em movimentos sociais a fim de contribuírem para mudanças institucionais e a importância que gestores e trabalhadores exercem ao incentivar a participação destes, pois as políticas são criadas para o "público" e portante devem ser criadas com o 
"público". No próximo eixo, analisaremos o processo de criação das políticas públicas, tendo como foco a avaliação destas.

Ciclo de políticas públicas

Nesse eixo trataremos de algumas etapas do ciclo de políticas públicas, também conhecido como processo de elaboração de políticas públicas. Secchi, Coelho e Pires (2019), resumiram esse processo em sete fases principais, conforme a Figura 2:

Figura 2 - Síntese das fases do ciclo de políticas públicas:

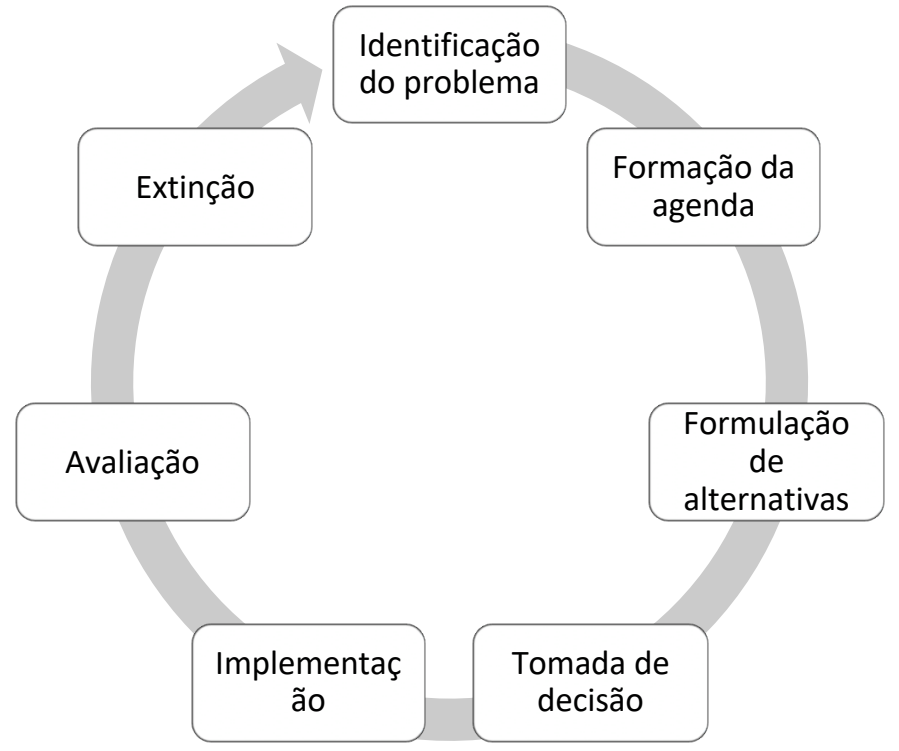

Fonte: Adaptado de Secchi, Coelho e Pires (2019).

Essas fases na realidade apresentam-se de forma sobreposta e não sequencial (SECCHI; COELHO; PIRES, 2019). Em muitos casos como podemos ver a seguir nos onze artigos selecionados para esse eixo. A fase do ciclo com maior destaque nos artigos é a avaliação das políticas públicas, devido a atual demanda indispensável por qualidade, eficiência e avaliação das políticas.

Pode-se afirmar, preliminarmente, que a avaliação é um instrumento importante para a melhoria da eficiência do gasto público, da qualidade da gestão, do controle social sobre a efetividade da ação do Estado, esse último instrumentalizado pela divulgação de resultados das ações de governo (RAMOS; SCHABBACH, 2012).

Para a avaliação de políticas públicas há duas abordagens (quantitativas e qualitativas), porém essas avaliações são sempre limitadas quando concentradas em apenas uma dessas abordagens. É importante ter uma estimativa precisa do impacto, principalmente para fundamentar decisões quanto à manutenção ou à extinção de programas governamentais (BATISTA; DOMINGOS, 2017). 
A prática de avaliação fortalece os arranjos institucionais e proporciona aos gestores a análise das políticas adotadas. No Brasil, as bases de dados públicas disponíveis apresentam problemas de confiabilidade, dados indisponíveis e descontinuidade na produção de indicadores; tais fatores podem contribuir com a baixa adesão a estudos avaliativos quantitativos (OLIVEIRA; PASSADOR, 2019).

Assim, as avaliações no Brasil estariam com maior quantidade de avaliações qualitativas de caráter local e com análise de políticas especificas, voltadas principalmente a prestação de contas e medição de desempenho e em busca da qualidade dos serviços prestados. Se mostra necessário pontuar a importância de ações avaliativas contínuas, principalmente em cenários com escassez de recursos financeiros, humanos e materiais. Tais avaliações podem contribuir com a destinação adequada dos recursos e o fortalecimento das ações de controle por parte dos órgãos responsáveis (OLIVEIRA; PASSADOR, 2019).

Porém há um crescente interesse dos governantes brasileiros com a avaliação, sendo relacionado às questões de efetividade, eficácia, eficiência, ao desempenho e à accountability da gestão pública. A avaliação permite ao governante certo conhecimento dos resultados de um dado programa ou projeto, informação essa que pode ser utilizada para melhorar a concepção ou a implementação das ações públicas, fundamentar decisões, promover a prestação de contas (RAMOS e SCHABBACH, 2012).

Na visão de Bichir (2015), no Brasil, especialmente após a redemocratização, os processos de produção de políticas públicas são cada vez mais complexos. Envolvem diversidade temática, grande número de atores estatais e não estatais em intricados padrões de interação e processos decisórios que se desenvolvem em distintas arenas, com consequências para públicos distintos. Construir modelos de análise para compreender a produção de políticas públicas, desde os processos decisórios até a implementação e a avaliação, não é uma tarefa trivial. Isso implica, no plano analítico, modelos explicativos que combinem distintas contribuições disciplinares por meio da articulação coerente de variados arsenais teóricos e metodológicos, para além de macro explicações por vezes superficiais.

Sobre as pesquisas científicas de avaliação em políticas públicas, um estudo comparando o Brasil e os Estados Unidos, os resultados encontrados permitem afirmar a proposição de que a pesquisa em avaliação ainda não está totalmente estabelecida como uma área de pesquisa no Brasil, assim como o é nos Estados Unidos. Apesar disso, esses resultados oferecem evidências de avanços na pesquisa em avaliação no Brasil (CRUMPTON et al., 2016). 
Outra evidência interessante é que, em ambos os países, as parcerias institucionais de pesquisadores para a análise e a avaliação de políticas não se restringem às universidades. Eles mantêm parcerias com organizações públicas que fornecem serviços aos cidadãos, tais como governos locais e departamentos de saúde do governo federal e de governos locais, o que sugere, portanto, que essas organizações estão assumindo papel ativo na pesquisa científica atual em relação à avaliação de políticas (CRUMPTON et al., 2016).

Os impactos das políticas públicas sobre a federação trouxeram várias inovações, como o reconhecimento dos direitos sociais, a universalização do acesso à saúde, aumento das competências concorrentes entre os três níveis de governo. Isso criou as bases para o desenho atual das políticas públicas, notadamente as sociais, com regulação federal e implementação quase sempre local. Essas inovações foram responsáveis pela capacidade de a União de contornar os dilemas federativos, conseguir a adesão das demais esferas à implementação e ao financiamento de políticas nacionais, também estimuladas por incentivos para sua adesão, e pela aprovação de emendas constitucionais que colocaram em prática alguns direitos sociais (SOUZA, 2019).

Ramos e Schabbach (2012), citam as dificuldades de realizar a avaliação de políticas públicas: muitos programas e ações não são desenhados para serem avaliados; a prevalência de delineamentos de pesquisa que não "controlam" as variáveis antecedentes, processuais e de resultados, e que produzem inferências espúrias, atribuindo ao programa a responsabilidade de resultados (bons ou ruins) não provocados por ele, mas por outros fatores; poucos dados disponíveis e, quando existentes, bastante limitados e com periodicidade irregular; a resistência na administração pública, devido à predominância de uma cultura autoritária.

Existe o constrangimento das autoridades públicas em relação a serem analisadas as suas ações e reagem através de: proibições diretas, ou colocação de dificuldades burocráticas: desinteresse no levantamento de dados, tornar inacessíveis as fontes, falta de apoio (RAMOS; SCHABBACH, 2012).

A fase da formulação é composta pelos processos de definição e escolha dos problemas que merecem a intervenção estatal, produção de soluções ou alternativas e tomada de decisão. A implementação refere-se à execução das decisões adotadas na etapa prévia. A avaliação consiste na interrogação sobre o impacto da política (LIMA; D'ASCENZI, 2013).

Lima e D'ascenzi (2013), identificaram dois modelos principais de implementação de políticas públicas, esses modelos enfatizam as condições materiais do desenvolvimento do processo de implementação. Os modelos apresentados 
diferenciam-se quanto ao foco de análise. O primeiro centra-se nas características da estrutura normativa, o segundo, nos atores implementadores e em suas ações. Em comum, as abordagens enfatizam as condições e limitações materiais, vistas como determinantes da trajetória do processo de implementação. Tal ênfase deixa espaço à inserção de variáveis ligadas às ideias, aos valores e às concepções de mundo dos atores.

Considerando que a implementação ocorre mediante uso de instrumentos governamentais, esses instrumentos determinam parcialmente quais recursos serão usados e por quem. Como qualquer outra instituição, os instrumentos permitem que formas de ação coletiva estabilizem e façam o comportamento dos atores ser mais previsível e provavelmente também mais visível. O estudo desses é de fundamental importância para resoluções de problemas e aperfeiçoamento do processo de implementação de políticas públicas (OLLAIK; MEDEIROS, 2011).

Sobre a continuidade de políticas públicas, ela pode ser afetada por diversos fatores relevantes, como, uma coalizão de interessados, problemas de coordenação e investimentos dos atores, quando presentes e em diferentes intensidades. A constitucionalização também é um fator e importa para a continuidade das políticas quando dispõe de mecanismos que a protegem: os cidadãos se mobilizam em sua defesa, as regras de emendamento são difíceis, e o judiciário é independente e dotado do poder de exercer o controle de constitucionalidade (COUTO; LIMA, 2016).

Por outro lado, a constituição é relevante quando a política não possui fontes de resiliência por si só: são poucos e/ou fracos os atores interessados na sua preservação, os problemas de coordenação em prol de uma alternativa podem ser facilmente superados, e a política não criou um processo de retroalimentação. Caso a política pública possua ou desenvolva tais mecanismos de sustentação, a importância da constitucionalização para sua continuidade diminui (COUTO; LIMA, 2016).

Em resumo nas políticas públicas de saúde, a epidemiologia contribui em todas as etapas do ciclo de políticas públicas. Na etapa de identificação dos problemas socialmente relevantes através do estudo da distribuição dos problemas de saúde e de seus determinantes nos diversos grupos sociais, fornecendo informações técnicas para embasar as decisões políticas. Na etapa de formulação das políticas, nos mecanismos de produção dos problemas de saúde e sobre a eficácia ou eficiência dos instrumentos de intervenção. Na etapa de implementação, a epidemiologia pode contribuir no acompanhamento através de tecnologias como a vigilância epidemiológica e o monitoramento. E no processo de avaliação é útil principalmente na análise dos impactos previstos e alcançados (BARATA, 2013). 
Diante do que foi exposto e baseado na pesquisa de Chaebo e Medeiros (2017), algumas propostas de pesquisa foram levantadas, como: relacionar a viabilidade econômica e aspectos democráticos, isto é, se a influência dos cidadãos nos rumos de política pública aumenta ou diminui a eficiência da relação de coprodução; outra estaria em relacionar arranjos institucionais, capacidade técnica e viabilidade econômica como fatores de ordem legal, técnica e econômica que afetam a dinâmica de implementação.

Na seção seguinte serão apresentadas as considerações finais do trabalho.

\section{Considerações Finais}

A partir da análise desses artigos foi possível compreender aspectos do desenvolvimento das políticas públicas brasileiras, seus envolvimentos com os atores e as fases do ciclo de políticas públicas.

Pode-se considerar recente a análise de políticas públicas no Brasil, porém com grandes avanços que sobrevieram a partir da Constituição Federal de 1988. Cada país tem suas particularidades, no Brasil é possível ver que a população está sofrendo uma alteração na pirâmide demográfica, o que afeta diretamente nas mudanças e adaptações das políticas públicas.

Um empecilho é o quadro dessas mudanças e a dissociação notada entre o planejamento orçamentário e as políticas públicas, o que dificulta a continuidade de ações, pois por mais que uma política tenha sido formulada com alta qualidade, sem os recursos adequados ela não atinge seu propósito, mostrando que a administração pública é essencial desde a formulação até a continuidade ou extinção de uma política.

As mudanças no cenário brasileiro, demostram a importância da formulação, implementação e avaliação de políticas públicas, este processo demanda a participação e formação de atores e movimentos sociais. A participação social e deliberativa já faz parte da democracia brasileira, ao menos a título de leis. Essas participações tem o poder de tornar as instituições representativas mais responsivas e, assim, ampliar a qualidade das democracias contemporâneas.

Quanto ao ciclo de políticas públicas, ganhou destaque a avaliação por ser um instrumento importante para a melhoria da eficiência do gasto público, da qualidade da gestão, do controle social sobre a efetividade da ação do Estado. Porém existem dificuldades para a realização destas avaliações, como a forma que foi desenhada, sem a percepção da importância da avaliação.

Quanto à continuidade das políticas públicas, notou-se que podem ser afetadas principalmente pela dissociação com o planejamento orçamentário, interesses políticos, coordenação e o acompanhamento social. 
Conclui-se que no Brasil a evolução das políticas públicas está diretamente ligada

à Constituição Federal, para a garantia de direitos dos cidadãos, os quais podem contribuir diretamente com a criação de políticas que supram suas necessidades e a continuidade destas.

Sugere-se para novas pesquisas avaliações práticas de políticas públicas que utilizem métodos quantitativos e qualitativos juntos, levando em consideração o desenho desta avaliação para que seja viável a execução. Assim como a realização de estudos, que possam verificar as novas dimensões de análise podendo contribuir para aumentar o entendimento sobre os resultados e a evolução das políticas públicas.

\section{Referências}

ABERS, Rebecca Neaera; SILVA, Marcelo Kunrath; TATAGIBA, Luciana. Movimentos sociais e políticas públicas: repensando atores e oportunidades políticas. Lua Nova, São Paulo, n. 105, p. 15-46, set. 2018.

ALMEIDA, Lia de Azevedo; GOMES, Ricardo Corrêa. Processo das políticas públicas: revisão de literatura, reflexões teóricas e apontamentos para futuras pesquisas. Cad. EBAPE.BR, Rio de Janeiro, v. 16, n. 3, p. 444-455, Set. 2018.

BARATA, Rita Barradas. Epidemiologia e políticas públicas. Rev. bras. epidemiol. São Paulo, v. 16, n. 1, p. 3-17, março de 2013.

BATISTA, Mariana; DOMINGOS, Amanda. Mais que boas intenções: técnicas quantitativas e qualitativas na avaliação de impacto de políticas públicas. Rev. bras. Ci. Soc., São Paulo, v. 32, n. 94, e329414, 2017.

BICHIR, Renata. Olhares cruzados nas análises de políticas públicas. Rev. bras. Ci. Soc., São Paulo, v. 30, n. 89, p. 175-181, Oct. 2015.

BORK, Anna Margherita Toldi. Enfermagem Baseada em evidências. Rio de Janeiro: Guanabara Koogan; 2005.

BRASIL. Ministério da Saúde. Secretaria de Ciência, Tecnologia e Insumos Estratégicos. Diretrizes metodológicas: elaboração de revisão sistemática e metanálise de ensaios clínicos randomizados. Brasília: Editora do Ministério da Saúde, 2012.

CAPES. Plataforma Sucupira. Qualis Periodicos. Classificassão de quadriênio 2013-2016, 2020.

CHAEBO, Gemael; MEDEIROS, Janann Joslin. Reflexões conceituais em coprodução de políticas públicas e apontamentos para uma agenda de pesquisa. Cad. EBAPE.BR, Rio de Janeiro, v. 15, n. 3, p. 615-628, July 2017.

COSTANZI, Rogério Nagamine; AMARAL, Aline Diniz; DIAS, Cicero Rafael; ANSILIERO, Graziela; AFONSO, Luis Eduardo; SIDONE, Otávio José Guerci. reforma da 
previdência social. In: IPEA - Instituto de Pesquisa Econômica Aplicada. Desafios da Nação, 2018, cap. 20.

COUTO, Cláudio Gonçalves; LIMA, Giovanna de Moura Rocha. Continuidade de Políticas Públicas: A Constitucionalização Importa?. Dados, Rio de Janeiro, v. 59, n. 4, p. 1055-1089, Out. 2016.

CRUMPTON, Charles David et al. Avaliação de políticas públicas no Brasil e nos Estados Unidos: análise da pesquisa nos últimos 10 anos. Rev. Adm. Pública, Rio de Janeiro, v. 50, n. 6, p. 981-1001, Dec. 2016.

DOWBOR, Monika; CARLOS, Euzeneia; ALBUQUERQUE, Maria do Carmo. As origens movimentistas de políticas públicas: proposta analítica aplicada às áreas de criança e adolescente, direitos humanos e saúde. Lua Nova, São Paulo , n. 105, p. 47-80, Sept. 2018.

FARAH, Marta Ferreira Santos. Análise de políticas públicas no Brasil: de uma prática não nomeada à institucionalização do "campo de públicas". Rev. Adm. Pública, vol.50, n.6, 2016.

FONSECA, Francisco. Dimensões críticas das políticas públicas. Cad.EBAPE.BR, Rio de Janeiro, v. 11, n. 3, 2013.

FRAGELLI, Thaís Branquinho Oliveira; SHIMIZU, Helena Eri. Prospecções para desenvolvimento de políticas públicas de formação de profissionais de saúde a partir da análise do cenário brasileiro de competências. Physis, Rio de Janeiro, v. 23, n. 1, p. 197-208, 2013.

FREITAS, Leana Oliveira. Políticas públicas, descentralização e participação popular. Rev. katálysis, Florianópolis, v. 18, n. 1, p. 113-122, June 2015.

GALVAO, Taís Freire; PEREIRA, Mauricio Gomes. Revisões sistemáticas da literatura: passos para sua elaboração. Epidemiol. Serv. Saúde, Brasília, v. 23, n. 1, p. 183184, mar. 2014.

KITCHENHAM, Barbara; CHARTERS, Stuart. Guidelines for performing systematic literature reviews in software engineering. Technical Report EBSE 2007-001, Keele University and Durham University Joint Report, 2007.

LIMA, Luciana Leite; D'ASCENZI, Luciano. Implementação de políticas públicas: perspectivas analíticas. Rev. Sociol. Polit. Curitiba, v. 21, n. 48, 2013.

LOTTA, Gabriela; FAVARETO, Arilson. Desafios da integração nos novos arranjos institucionais de políticas públicas no Brasil. Rev. Sociol. Polit., Curitiba, v. 24, n. 57, p. 49-65, mar. 2016. 
MACEDO, Alex dos Santos et al. O papel dos atores na formulação e implementação de políticas públicas: dinâmicas, conflitos e interesses no Programa Mais Médicos. Cad. EBAPE.BR, Rio de Janeiro, v. 14, n. spe, p. 593-618, 2016.

MACIEL, Pedro Jucá. Finanças públicas no Brasil: uma abordagem orientada para políticas públicas. Rev. Adm. Pública, Rio de Janeiro, v. 47, n. 5, p. 1213-1241, Oct. 2013.

MIRANDA, Gabriella Morais Duarte; MENDES, Antonio da Cruz Gouveia; SILVA, Ana Lucia Andrade da. Desafios das políticas públicas no cenário de transição demográfica e mudanças sociais no Brasil. Interface, Botucatu, v. 21, n. 61, p. 309-320, June 2017.

NASCIMENTO, Sueli do. Reflexões sobre uma intersetorialidade entre as políticas públicas. Serv. Soc. Soc. São Paulo, n. 101, p. 95-120, 2010.

OLIVEIRA, Lilian Ribeiro de; PASSADOR, Claudia Souza. Ensaio teórico sobre as avaliações de políticas públicas. Cad. EBAPE.BR, Rio de Janeiro , v. 17, n. 2, p. 324337, 2019.

OLLAIK, Leila Giandoni; MEDEIROS, Janann Joslin. Instrumentos governamentais: reflexões para uma agenda de pesquisas sobre implementação de políticas públicas no Brasil. Rev. Adm. Pública, Rio de Janeiro, v. 45, n. 6, p. 1943-1967, 2011.

PETINELLI, Viviane. Aferindo a capacidade de influência das conferências de políticas públicas sobre os programas das respectivas políticas setoriais. Opin. Publica, Campinas, v. 21, n. 3, p. 643-672, 2015.

PETINELLI, Viviane. A quem serve como reuniões de políticas públicas? Desenho institucional e atores beneficiados. Opin. Publica, Campinas, v. 23, n. 3, p. 612-646, 2017.

POGREBINSCHI, Thamy; VENTURA, Tiago. Mais Participação, Maior Responsividade? As Conferências Nacionais de Políticas Públicas e a Qualidade da Democracia no Brasil. Dados, Rio de Janeiro, v. 60, n. 1, p. 7-43, Mar. 2017.

RAMOS, Marília Patta; SCHABBACH, Letícia Maria. O estado da arte da avaliação de políticas públicas: conceituação e exemplos de avaliação no Brasil. Rev. Adm. Pública, Rio de Janeiro, v. 46, n. 5, p. 1271-1294, Oct. 2012.

SANTOS, Reginaldo Souza et al. Administração política e políticas públicas: em busca de uma nova abordagem teórico-metodológica para a (re)interpretação das relações sociais de produção, circulação e distribuição. Cad. EBAPE.BR, Rio de Janeiro, v. 15, n. 4, p. 939-959, 2017. 


\section{Obsevisto}

SECCHI, Leonardo; COELHO, Fernando de Souza; PIRES, Valdemir. Políticas públicas: conceitos, categorias de análise, casos práticos. 3. ed. São Paulo: Cengage Learning, 2019.

SILVA, Rogério Luiz Nery da. Políticas públicas e administração democrática. Sequência, Florianópolis, n. 64, p. 57-85, 2012.

SMITH, Kevin B.; LARIMER, Christopher W. The Public Policy Theory Primer. Boulder- CO, Westview Press. 2009.

SOUZA, Celina Maria de. Coordenação, uniformidade e autonomia na formulação de políticas públicas: experiências federativas no cenário internacional e nacional. Cad. Saúde Pública, Rio de Janeiro, v. 35, supl. 2, 2019.

VALLE, Vanice Lírio do. Planejamento orçamentário e políticas públicas: explorando uma alternativa de reconciliação pela indução. Rev. Investig. Const., Curitiba, v. 5, n. 2, p. 113-134, Aug. 2018.

VAZ, Alexander Cambraia N. Participação política, efeitos e resultados em políticas públicas: notas crítico-analíticas. Opin. Publica, Campinas, v. 17, n. 1, p. 163-205, June 2011. 


\section{Crevisto Observatório}

\section{ABSTRACT:}

This study aimed to analyze the evolution of public policies in the academic publications in Brazil from 2010 to 2019, from the perspective of their development, performances of the actors and social movements and the development of the public policy cycle phases. Thirty relevant studies were considered and in accordance with an issue addressed. An analysis enabled the division of articles into thematic axes, to presents the results and discussion about public policies in Brazil, actors and social movements and the public policy cycle. A recent analysis of public policies in Brazil can be considered, but with great advances after new federal constitution.

KEYWORDS: Public Management; Public Policies; Public Policy Cycle.

\section{RESUMEN:}

Este estudio tuvo como objetivo analizar la evolución de las políticas públicas en Brasil de 2010 a 2019, desde la perspectiva de su desarrollo, la participación de los actores y movimientos sociales y el desarrollo de las fases del ciclo de políticas públicas. Se identificaron treinta estudios relevantes y de acuerdo con el problema abordado. El análisis permitió dividir los artículos en ejes temáticos, para exponer mejor los resultados y la discusión, a saber: el contexto de las políticas públicas en Brasil, los actores y los movimientos sociales y el ciclo de las políticas públicas. El análisis de las políticas públicas en Brasil puede considerarse reciente, pero con los grandes avances que provienen de la Constitución Federal.

PALABRAS-CLAVES: Gestión Pública. Políticas públicas. Ciclo de Políticas Públicas. 